\title{
Hypoglycaemic Agents in Patients with Heart Failure
}

\author{
Giuseppe MC Rosanoํㄹ Petar Seferović 2
}

1. Centre for Clinical \& Basic Research IRCCS San Raffaele Pisana, via della Pisana, 235, 00163 Rome, Italy

2. President, Heart Failure Association of the ESC and Professor of Internal Medicine/Cardiology at Belgrade University School of Medicine, and the Heart Failure Department, University Medical Center Belgrade, Belgrade, Serbia.

\section{Corresponding author:}

Professor Giuseppe M.C. Rosano,

Centre for Clinical \& Basic Research IRCCS San Raffaele Pisana,

via della Pisana, 235, 00163 Rome, Italy

Email: giuseppe.rosano@gmail.com

\begin{abstract}
Impaired glucose metabolism and diabetes are both very common in HF, and associated with worse functional status and prognosis. More lenient rather than strict glycaemic control is advised in patients with HF. In patients with diabetes and HF glycaemic control should be implemented gradually and moderately, giving preference to those drugs that have been shown to be safe and effective. SGLT2 inhibitors improve CV outcomes and reduce the risk of hospitalisations for heart failure, and are as a result the preferred glucose-lowering agents in T2DM patients at risk for, or with, established HF. Metformin is considered safe in $\mathrm{HF}$ with diabetes and is a preferred agent for glycaemic control in this setting. Sulfonylurea treatment seems to be associated with a higher risk of HF hospitalisation and is not indicated in patients with heart failure. GLP-1 receptor agonists have been proven to reduce macrovascular end points in patients with type II diabetes, however, they seem at most ineffective in patients with HF with reduced ejection fraction, and are not therefore the preferred agents in this patient population. DPP-4 inhibitors (gliptins) have only a limited effect on glucose control and no benefit on cardiovascular events and therefore do have compelling arguments for use in HF patients with type 2 diabetes.
\end{abstract}

Keywords: heart failure; diabetes mellitus; therapy; SGLT2 inhibitors

Citation: $\quad$ Rosano GMC Seferović P. Hypoglycaemic Agents in Patients with Heart Failure. International Cardiovascular Forum Journal. 2019;18:31-35. DOI: 10.17987/icfj.v18i0.623

\section{Introduction}

Impaired glucose metabolism and diabetes are very common in heart failure (HF), and diabetes is associated with poorer functional status and worse prognosis in patients with HF. Glucose control improves microvascular, and to a certain extent also macrovascular complications in diabetic patients. However, whether strict glycaemic control adds benefits greater than its risks compared to more lenient glycaemic control in improving the risk of cardiovascular (CV) events in patients with $\mathrm{HF}$ is uncertain. Amongst untreated diabetic patients with $\mathrm{HF}$ a higher Hemoglobin $\mathrm{A} 1 \mathrm{c}(\mathrm{HbA} 1 \mathrm{c})$ is associated with a greater risk of future $\mathrm{CV}$ events. However, this is not the case once treatment for diabetes has been implemented. Furthermore, observational data suggest that aggressive glucose control is associated with an increased risk of events in diabetic patients with heart failure. In patients with diabetes and HF glycaemic control should be implemented gradually and moderately, giving preference to those drugs that have been shown to be safe and effective.[1]
It is well known that in diabetic patients with HF, insulin and glucose-lowering agents that cause sodium retention increase the risk of worsening HF and hospitalisation.

In the past decade a new wave of glucose lowering agents has become available for the management of diabetes and much new data on their long-term safety has become more recently available. For some of these drugs conflicting results have been reported, for some others the safety profile in HF has not been adequately characterized whilst for others a significant benefit in preventing HF has been suggested.

\section{Metformin}

The glucose lowering mechanism of metformin is predominantly due to a decrease in hepatic glucose production. Therefore, these drugs do not directly affect insulin sensitivity. Metformin is at the present the only available biguanide and it has been developed in an era when it was supposed that glucose lowering per se would be safe and have beneficial effects on CV outcome, so that only evidence of hypoglycaemic efficacy was deemed 
necessary if standard safety signals had been excluded. Therefore, there are no large randomised trials available on the CV safety and efficacy of metformin. The only randomised trial with metformin in patients with new onset of diabetes was the UK Prospective Diabetes Study (UKPDS) 34.[2] The study found a significant reduction in CV outcomes with metformin compared to sulfonylureas and insulin in obese diabetic patients. Cohort studies [3] reported a superiority on HF outcomes of metformin over sulfonylureas or glitazones. Subsequently, meta-analyses reported a superiority of metformin over other glucose lowering drugs in reducing cardiovascular events and heart failure in an unselected population of diabetic patients.

Heart failure had long been considered a contraindication for the use of metformin because of concerns regarding an increased risk of precipitating lactic acidosis. However, cohort studies assessed the effect of metformin in patients with HF treated with metformin and did not find a significant risk. A meta-analysis of most of the available studies included 34,000 diabetic patients with heart failure.[4] Metformin was found to reduce by $20 \%$ the relative risk of worsening heart failure and death compared to other glucose lowering drugs. Two studies that have investigated the effect of metformin in patients with heart failure found a nonsignificant trend towards a beneficial effect of metformin.[5,6]

Kidney dysfunction is a relative contraindication for metformin as it reduces the renal elimination of the drug. However, Aguilar et al. found that in patients with HF and diabetes there was no interaction between kidney function and outcomes. Instead they found a clear trend for beneficial effects of metformin especially in patients with a glomerular filtration rate $<60$.[5]

As mentioned above for the reason that metformin has been developed more than 30 years ago proper randomised studies on its safety and efficacy in patients with, or at high risk to develop, $\mathrm{HF}$ are lacking. It is fair to conclude, however, that with the large number of patients included in retrospective cohort studies, no evidence of safety concerns in those patients at risk for HF has been seen.

\section{Sulfonylureas in HF}

Like biguanides, the cardiovascular safety of sulfonylureas has never been prospectively tested. Available cohort studies with this class of drugs are heterogeneous and have shown neutral or increased CV event rates in diabetic patients. The situation with sulfonylureas is more complicated than for metformin, since several sulfonylureas have become commercially available.

There are no specific studies investigating patients with HF and diabetes. Therefore, the knowledge on the effect of this class of drugs is deduced from unselected cohorts of diabetic patients who developed heart failure.

A recent propensity score matched analysis of 130,000 patients found an inferiority of sulfonylureas in direct comparison to metformin users with respect to HF hospitalization rates.[7] In this unselected cohort of diabetic patients, the hospitalisations for heart failure were significantly increased by sulfonylurea treatment. In another analysis in more than 300,000 diabetic patients [8] a similar risk of heart failure was found for sulfonylureas and acarbose compared to an increased risk with glinide treatment. Prevalent HF in this study was rare and even cardiac co-morbidity was less than $20 \%$. A third cohort study [9] including nearly 500,000 patients reported an increased risk for HF hospitalisations with sulfonylureas and insulin compared to non-users, and a decreased risk for glitazones, gliptins and metformin.

Therefore, in unselected diabetic cohorts sulfonylurea treatment seems to be associated with a higher risk of HF hospitalisation compared to metformin, gliptins or glitazones and a similar risk compared to insulin or acarbose. Due to the complete lack of data in diabetic patients with HF, and considering the signals of an increased risk for HF, sulfonylureas are not indicated in patients with heart failure.

\section{DPP-4 inhibitors}

The DPP-4 inhibitors (gliptins) stimulate insulin secretion by increasing plasma levels of incretins.[10] Three large scale randomized clinical trials have been performed to assess the $\mathrm{CV}$ safety of DPP-4 inhibitors to date. These studies were designed to demonstrate non-inferiority of these molecules against placebo and recruited diabetic patients at increased CV risk. All DPP-4 inhibitors outcome trials met the primary composite endpoint of non-inferiority versus placebo (combinations of $\mathrm{CV}$ death, non-fatal MI, non-fatal stroke etc.). It is important to remind ourselves, however, of the purpose of a non-inferiority end-point. If we are comparing a new treatment with established therapy we may be comfortable knowing we can exclude the fact that the new drug is significantly worse than established treatment within a pre-set limit, if for example it had other advantages, in tolerability or price for example. If the comparator in a noninferiority trial is placebo, however, all we can say with a positive trial is that the new drug is no worse than placebo (or nothing!). This would only be acceptable to guide clinical use if some other worthwhile benefit had been shown, and if that is merely a reduction in glucose levels with no outcome benefits, this may not be convincing enough to adopt the new drug into clinical practice. The primary end-points of these three trials therefore merely show that these drugs have a small glucose lowering effect and are not worse than placebo in reducing CV events. Indeed they were not shown to be significantly better either. In the three trials although major cardiac events were not different to placebo, the incident hospitalization rates for HF differed. The Saxagliptin Assessment of Vascular Outcomes Recorded in patients with diabetes mellitus - Thrombolysis In Myocardial Infarction 53 (SAVOR-TIMI 53) [11] studied 16,492 patients with type 2 diabetes with or at risk for CV events for a median of 2.1 years. The primary end point (the composite of CV death, MI, or ischemic stroke) did not differ $(1.00 ; 95 \% \mathrm{Cl}, 0.89$ to 1.12 ; $\mathrm{P}=0.99$ for superiority; $\mathrm{P}<0.001$ for non-inferiority), however, a statistically significant $27 \%$ increase in hospitalisation for HF was observed in the patients randomised to saxagliptin as compared to placebo ( $3.5 \%$ vs $2.8 \%$; $p=0.007$ ). The alogliptin in Examination of Cardiovascular Outcomes vs Standard of Care in Patients with Type 2 Diabetes and Acute Coronary Syndrome (EXAMINE) trial assessed 5,380 patients with type 2 diabetes and either an AMI or unstable angina requiring hospitalization within the previous 15 to 90 with non-inferiority primary end point of the composite of CV death, nonfatal MI, or nonfatal stroke.[12] The primary (HR, 0.96; $\mathrm{P}<0.001$ for non-inferiority) showed neither risk nor benefit on the background of a mean difference of -0.36 percentage 
points in glycated $\mathrm{Hb} .(\mathrm{P}<0.001)$. However there was a nonsignificant increased risk of hospitalisations for $\mathrm{HF}$ with alogliptin (HR 1.19; 95\% Cl 0.90-1.58) in the same direction as that seen with saxagliptin. The Trial Evaluating Cardiovascular Outcome with Sitagliptin (TECOS) [13] randomised 14,671 type 2 diabetics aged at least 50 and with established CV disease for a median follow-up of 3.0 years, leading to a small average difference in glycated hemoglobin levels of -0.29 percentage points. The primary outcome (the composite of CV mortality, nonfatal MI, nonfatal stroke, or hospitalization for unstable angina) did not differ ( $\mathrm{HR}, 0.98)$ and in this case the rate of hospitalization for heart failure also did not differ between the two groups $(\mathrm{HR}, 1.00$; $95 \% \mathrm{Cl}, 0.83$ to $1.20 ; \mathrm{P}=0.98$ ).

Meta-analyses of the 3 randomised controlled studies consistently reported an increased risk of HF hospitalisations with DPP4is as a group, even thought he three individual trials differed in this regard. The US FDA released a drug safety communication about the potential increase in the risk of HF with saxagliptin and alogliptin but not with sitagliptin.[14-15] Such heterogeneous results raised concerns of increased HF hospitalization risk for DPP-4 inhibitors as a whole as stated in 2016 ESC HF guidelines.[1] The Cardiovascular and Renal Microvascular Outcome Study with Linagliptin in patients with type 2 diabetes (CARMELINA) [16] was significant for noninferiority against placebo on MACE but also showed no benefit in any other CV end-point including hospitalisations for heart failure. The Cardiovascular Outcome Study of Linaglitpin versus Glimepiride in Patients with Type 2 Diabetes (CAROLINA) [17] will help address the differences in $\mathrm{CV}$ risk of the two drugs. However, this is a class of drug with only a limited effect on glucose control and no difference to placebo with regard to cardiovascular events does not appear to have compelling arguments for use in HF patients with type 2 diabetes. Given the high cost of these medications it is difficult to justify their clinical use in this regard.

\section{SGLT-2 inhibitors in HF}

SGLT-2 inhibitors are glucose lowering drugs that block the SGLT-2 receptors in the proximal tubule of the kidney, thus leading to increased urinary glucose excretion along with sodium. [18-19] Three SGLT-2 inhibitors - canagliflozin, dapagliflozin, and empagliflozin - have been approved for the treatment of T2DM by regulatory agencies in Europe and United States. Recently three landmark trials reported that SGLT-2 inhibitors demonstrated remarkable improvements in CV outcomes especially hospitalisation for HF in patients with T2DM, beyond lipid lowering.

The Empagliflozin Cardiovascular Outcome Event Trial in Type 2 Diabetes Mellitus Patients Removing Excess Glucose (EMPAREG OUTCOME) [20] randomised 7,020 patients with T2DM and established CV disease to receive $10 \mathrm{mg}$ or $25 \mathrm{mg}$ of empagliflozin or placebo once daily. After a median observation time of 3.1 years, empagliflozin (pooled $10 \mathrm{mg}$ and $25 \mathrm{mg}$ doses) showed a significant $14 \%$ relative risk reduction (RRR) in the primary composite endpoint of $\mathrm{CV}$ death, nonfatal myocardial infarction or nonfatal stroke. Moreover empagliflozin significantly reduced death from $\mathrm{CV}$ causes, death from any cause and hospitalisation for $\mathrm{HF}$ by $38 \%, 32 \%$ and $35 \%$ respectively. Empagliflozin was also associated with slower progression of renal disease than was placebo.[21] Post-hoc analysis of the EMPA-REG OUTCOME trial demonstrated that empagliflozin reduced HF hospitalisation and CV death consistently in patients with, and without baseline HF.[22] The Canagliflozin Cardiovascular Assessment Study (CANVAS) Program, integrated data from two trials involving a total of 10,142 participants with T2DM and high CV risk.[23] Participants were randomised to canagliflozin or placebo and after a mean follow-up of 188.2 weeks canagliflozin showed a significant $14 \%$ RRR in the primary composite endpoint of CV death, nonfatal myocardial infarction, or nonfatal stroke. Canagliflozin significantly reduced the risk of hospitalisation for $\mathrm{HF}$ and a renal composite outcome by $33 \%$ and $40 \%$ respectively. The study reported however a disturbing increase in amputations in patients receiving canagliflozin.

More recently the Dapagliflozin Effect on CardiovascuLAR Events study (DECLARE) evaluated 17,160 patients, of which 10,186 without atherosclerotic cardiovascular disease for a median of 4.2 years.[24] In the primary outcome analysis, dapagliflozin met the prespecified criterion for noninferiority to placebo. In the two primary efficacy analyses, dapagliflozin did not reduce significantly MACE (8.8\% vs $9.4 \%$; hazard ratio, $0.93 ; 95 \% \mathrm{Cl}, 0.84$ to 1.03 ; $\mathrm{P}=0.17$ ) but did show a $17 \%$ lower rate of cardiovascular death or hospitalization for heart failure $(4.9 \%$ vs. $5.8 \%$; hazard ratio, $0.83 ; 95 \% \mathrm{Cl}, 0.73$ to $0.95 ; \mathrm{P}=0.005)$. The rate of hospitalization for heart failure was reduced by $27 \%(\mathrm{HR} 0.73 ; 95 \% \mathrm{Cl}, 0.61$ to 0.88). Renal events were reduced by $14 \%$ by dapagliflozin (HR, $0.76 ; 95 \% \mathrm{Cl}, 0.67$ to 0.87 ). Therefore, the study demonstrated a significantly lower rate of cardiovascular death or hospitalization for heart failure in a population with a baseline risk lower than that of patients included in EMPA-REG and CANVAS.

The effect on HF hospitalisation was not among elements of composite primary endpoint in the EMPA-REG OUTCOME and CANVAS trials but it was in DECLARE where it was specifically adjudicated. Importantly these three trials showed early, marked and sustained benefit with STGL2i in terms of HF hospitalisation. This class of drugs seems to have, beyond glucose lowering, several important haemodynamic, neurohumoral, renal, metabolic and vascular favourable effects which might have contributed to positive outcomes. The increased risk of amputation, bone fractures and volume depletion with canagliflozin is a concern that relates only to this compound.

The positive findings of these trials suggest a class effect of SGLT2 inhibitors [38] at least for HF and renal related outcomes. This is supported by the findings of CVD-REAL study which assessed real-life data of 309,056 patients with T2DM across 6 countries. [25]. Compared with other T2DM agents, SGLT-2 inhibitors were associated with $39 \%$ RRR of HF hospitalisation and 51\% RRR of death from any cause. The reduction in CV MACE end-points seen with two agents may not be a class effect as it was not seen with Dapagliflozin. As this class of agent improves CV outcome and reduces the risk of hospitalisations for heart failure, SGLT2 inhibitors should be the preferred glucose-lowering agents in T2DM patients at risk for, or with, established HF.

\section{Glucagon-like peptide 1 (GLP-1) receptor agonists and the risk of HF}

Glucagon-like peptide 1 (GLP-1) has a number of physiological effects. The main effect is stimulating glucose-dependent insulin 
release from the pancreatic islets but it also inhibits inappropriate post-prandial glucagon release and reduces food consumption. [26] The GLP-1 receptor agonists have been tested in large outcomes trials in patients with type II diabetes mellitus. The ELIXA trial which enrolled 6,068 patients within 180 days of an acute coronary syndrome, showed that the GLP-1 receptor agonist lixisenatide did not increase the risk of hospitalisation for HF (HR 0.96, 95\% Cl 0.75-1.23, $\mathrm{p}=0.75$ ).[27], but it also failed to reduce the primary endpoint of the trial (a composite of CV death, myocardial infarction, stroke or hospitalisation for unstable angina), so it was a neutral trial.

In contrast, the LEADER trial that included 9,340 diabetic patients showed that liraglutide reduce the primary composite endpoint of CV death, myocardial infarction or stroke by $13 \%$. [28] The study failed to show a significant reduction in the risk of hospitalisation for HF ( $\mathrm{HR}=0.87,95 \% \mathrm{Cl} 0.73-1.05, \mathrm{p}=0.14)$. Similarly, in SUSTAIN-6, a shorter trial of 2.1 years including 3,297 diabetic patients, the rate of HF hospitalisation was not reduced by the once weekly GLP-1 receptor agonist semaglutide ( $H R=1.11,95 \%$ I 0.77-2.78, $p=0.57$ ) (29), despite a significant reduction in the primary end-point (composite of CV death, nonfatal $\mathrm{MI}$, or nonfatal stroke) (HR, 0.74; 95\% Cl, 0.58 to $0.95, p<0.02$ for superiority), despite it being formally a non-inferiority trial.

In the LIVE trial 241 patients with heart failure and an ejection fraction of $\leq 45 \%$ ( $30 \%$ had type II diabetes mellitus) were randomised to liraglutide or placebo for 24 weeks. [30] No change in left ventricular ejection fraction between the two groups was detected, heart rate increased in the liraglutide group. Serious adverse cardiac events were statistically significantly higher in the liraglutide group casting some clouds over the safety of these drugs in patients at increased risk, or with diagnosed heart failure. Therefore, GLP-1 receptor agonists have been proven to reduce macrovascular end points in patients with type II diabetes, however, they seem at most ineffective in patients with HF with reduced ejection fraction, and are not therefore the preferred agents in this patient population.

\section{Insulin and the risk of heart failure}

Insulin increases sympathetic activity and $\mathrm{Na}$ retention. Therefore, it is theoretically detrimental for patients with heart failure. The anti-natriuretic effect of insulin is evident even in physiological concentrations[31], and the sodium-retaining effect of insulin on the kidney is not affected by insulin resistance existing in other tissues.[32] Fluid retention caused by insulin may contribute to weight gain, and may lead to worsening of HF. Insulin may also cause hypoglycemia which has been associated with poor CV outcomes, including HF. The CHARM trial suggested higher risk of HF and worse outcomes in heart failure patients on insulin compared to those using oral glucoselowering agents.[33] The UKPDS trial [34] did not find any significant difference in the incidence of HF between patients receiving insulin or sulphonylureas. The ORIGIN trial [35] in 12,537 patients with different levels of altered glucose metabolism and CV risk factors randomized to basal insulin glargine or control, showed no differences in cardiovascular outcomes, including HF hospitalization, but was comparing insulin glargine with other anti-diabetic medication, some of which have subsequently been shown to increase the risk of HF. The DEVOTE trial [36] found that the ultralong-acting insulin degludec was non-inferior to glargine with respect to the incidence of major cardiovascular events. Nevertheless, hospitalization for HF was not included in the primary composite outcome and was also not a secondary end-point in this trial. Although current data suggest mostly neutral effects of insulin therapy on HF outcomes, future clinical trials are needed to address the therapeutic benefits of these agents. Insulin should be, however, avoided as much as possible in patients with heart failure because of the risk of precipitating $\mathrm{HF}$ hospitalization, and the lack of clear evidence of benefit in terms of major CV outcomes in HF patients.

\section{Conclusions}

Glucose lowering agents may increase the risk of cardiovascular events especially when a tight glycaemic control strategy is pursued. After the withdrawal of Rosiglitazone, a thiazolidinedione, from the European market because of an increased risk of $\mathrm{CV}$ events including heart failure, the negative effect of glucose lowering agents in patients with HF or at increased risk of HF has become more evident.

Therefore, glucose lowering treatment should be carefully evaluated and gradually implemented in diabetic patients with $\mathrm{HF}$ and in patients at increased risk of developing heart failure. In the management of diabetic patients with HF preference should be given to drugs that have been shown to be safe and effective. Metformin can be safely used in diabetic patients with HF but caution should be exerted in patients with impaired renal function. Sulphonylureas may increase the risk of worsening HF, possibly related to hypoglycaemia and, therefore, should be avoided

Metiglinides and insulin may induce water retention and should be used with caution in patients with HF. Alpha glucosidaseinhibitors are devoid of any effect on insulin, water and Na retention, and are safe to use in patients with HF. Thiazolidinediones are increase the risk of HF worsening and hospitalisations from HF and they are contraindicated in patients with HF. DPP-4 inhibitors have a small effect on glucose control especially given their high cost. As there remain are doubts concerning their safety in $\mathrm{HF}$, they should not be routinely used in patients with heart failure. GLP-1 receptor agonists seem to be safe to use in patients with HF. There is ample evidence to support the use of SGLT-2 as a class as the drugs of choice for the treatment of diabetes mellitus in patients with heart failure.

\section{Declarations of interest}

The authors declare no conflict of interest.

\section{Acknowledgements}

The authors state that they abide by the authors' responsibilities and ethical publishing guidelines of the International Cardiovascular Forum Journal.[37]

\section{References}

1. Ponikowski P, Voors AA, Anker SD, Bueno H, Cleland JG, Coats AJ, Falk V, Gonzalez-Juanatey JR, Harjola VP, Jankowska EA, Jessup M, Linde C, Nihoyannopoulos P, Parissis JT, Pieske B, Riley JP, Rosano GM, Ruilope LM, Ruschitzka F, Rutten FH, van der Meer P, Authors/Task Force M, Document R. 2016 ESC Guidelines for the diagnosis and treatment of acute and chronic heart failure: The Task Force for the diagnosis and treatment of acute and chronic heart failure of the European Society of Cardiology (ESC). Developed with the special contribution of the Heart Failure Association (HFA) of the ESC. European journal of heart failure. 2016;18(8):891-975. 
2. UK Prospective Diabetes Study (UKPDS) Group. Effect of intensive bloodglucose control with metformin on complications in overweight patients with type 2 diabetes (UKPDS 34). Lancet. 1998;352(9131):854-65.

3. Varas-Lorenzo C, Margulis AV, Pladevall M, Riera-Guardia N, Calingaert B, Hazell L, Romio S, Perez-Gutthann S. The risk of heart failure associated with the use of noninsulin blood glucose-lowering drugs: systematic review and meta-analysis of published observational studies. BMC cardiovascular disorders. 2014;14:129.

4. Eurich DT, Weir DL, Majumdar SR, Tsuyuki RT, Johnson JA, Tjosvold L, Vanderloo SE, McAlister FA. Comparative safety and effectiveness of metformin in patients with diabetes mellitus and heart failure: systematic review of observational studies involving 34,000 patients. Circulation Heart failure. 2013;6(3):395-402

5. Aguilar D, Chan W, Bozkurt B, Ramasubbu K, Deswal A. Metformin use and mortality in ambulatory patients with diabetes and heart failure. Circulation Heart failure. 2011;4(1):53-8.

6. Shah DD, Fonarow GC, Horwich TB. Metformin therapy and outcomes in patients with advanced systolic heart failure and diabetes. Journal of cardiac failure. 2010;16(3):200-6.

7. Roumie CL, Min JY, D'Agostino McGowan L, Presley C, Grijalva CG, Hackstadt AJ, Hung AM, Greevy RA, Elasy T, Griffin MR. Comparative Safety of Sulfonylurea and Metformin Monotherapy on the Risk of Heart Failure: A Cohort Study. Journal of the American Heart Association. 2017;6(4).

8. Lee YC, Chang CH, Dong YH, Lin JW, Wu LC, Hwang JS, Chuang LM. Comparing the risks of hospitalized heart failure associated with glinide, sulfonylurea, and acarbose use in type 2 diabetes: A nationwide study. International journal of cardiology. 2017;228:1007-14.

9. Hippisley-Cox J, Coupland C. Diabetes treatments and risk of heart failure, cardiovascular disease, and all cause mortality: cohort study in primary care. Bmj. 2016;354:i3477.

10. Nauck M. Incretin therapies: highlighting common features and differences in the modes of action of glucagon-like peptide-1 receptor agonists and dipeptidyl peptidase-4 inhibitors. Diabetes, obesity \& metabolism. 2016;18(3):203-16

11. Scirica BM, Braunwald E, Raz I, Cavender MA, Morrow DA, Jarolim P, Udell JA, Mosenzon O, Im K, Umez-Eronini AA, Pollack PS, Hirshberg B, Frederich R, Lewis BS, McGuire DK, Davidson J, Steg PG, Bhatt DL, Committee S-TS, Investigators*. Heart failure, saxagliptin, and diabetes mellitus: observations from the SAVOR-TIMI 53 randomized trial. Circulation. 2014;130(18):1579-88.

12. Zannad F, Cannon CP, Cushman WC, Bakris GL, Menon V, Perez AT, Fleck PR, Mehta CR, Kupfer S, Wilson C, Lam H, White WB, Investigators E. Heart failure and mortality outcomes in patients with type 2 diabetes taking alogliptin versus placebo in EXAMINE: a multicentre, randomised, doubleblind trial. Lancet. 2015;385(9982):2067-76.

13. Green JB, Bethel MA, Armstrong PW, Buse JB, Engel SS, Garg J, Josse R, Kaufman KD, Koglin J, Korn S, Lachin JM, McGuire DK, Pencina MJ, Standl E, Stein PP, Suryawanshi S, Van de Werf F, Peterson ED, Holman RR, Group TS. Effect of Sitagliptin on Cardiovascular Outcomes in Type 2 Diabetes. The New England journal of medicine. 2015;373(3):232-42.

14. FDA. Diabetes medications containing saxagliptin and alogliptin: drug safety communication - risk of heart failure. Available from: https://www.fda.gov/safety/medwatch/safetyinformation/ safetyalertsforhumanmedicalproducts/ucm494252.htm. 2016.

15. Fadini GP, Avogaro A, Degli Esposti L, Russo P, Saragoni S, Buda S, Rosano G, Pecorelli S, Pani L, OsMed Health DBN. Risk of hospitalization for heart failure in patients with type 2 diabetes newly treated with DPP-4 inhibitors or other oral glucose-lowering medications: a retrospective registry study on 127,555 patients from the Nationwide OsMed Health-DB Database. European heart journal. 2015;36(36):2454-62.

16. Rosenstock J, Perkovic V, Johansen OE, et al. Effect of Linagliptin vs Placebo on Major Cardiovascular Events in Adults With Type 2 Diabetes and High Cardiovascular and Renal Risk: The CARMELINA Randomized Clinical Trial. JAMA. 2019;321(1):69-79. doi:10.1001/jama.2018.18269

17. Clinical.trial.gov CAROLINA: Cardiovascular Outcome Study of Linaglitpin Versus Glimepiride in Patients with Type 2 Diabetes. http://clinicaltrialsgov/ ct2/show/NCT01243424? term=CAROLINA+linagliptin\&rank=1. Accessed 5 December 2017. 2017.

18. Marx N, McGuire DK. Sodium-glucose cotransporter-2 inhibition for the reduction of cardiovascular events in high-risk patients with diabetes mellitus. European heart journal. 2016;37(42):3192-200.

19. Verbrugge FH. Role of SGLT2 Inhibitors in Patients with Diabetes Mellitus and Heart Failure. Current heart failure reports. 2017;14(4):275-83

20. Zinman B, Wanner C, Lachin JM, Fitchett D, Bluhmki E, Hantel S, Mattheus M, Devins T, Johansen OE, Woerle HJ, Broedl UC, Inzucchi SE, Investigators E-RO. Empagliflozin, Cardiovascular Outcomes, and Mortality in Type 2 Diabetes. The New England journal of medicine. 2015;373(22):2117-28.

21. Wanner C, Inzucchi SE, Lachin JM, Fitchett D, von Eynatten M, Mattheus M, Johansen OE, Woerle HJ, Broedl UC, Zinman B, Investigators E-RO. Empagliflozin and Progression of Kidney Disease in Type 2 Diabetes. The New England journal of medicine. 2016;375(4):323-34.

22. Fitchett D, Zinman B, Wanner C, Lachin JM, Hantel S, Salsali A, Johansen OE, Woerle HJ, Broedl UC, Inzucchi SE, investigators E-ROt. Heart failure outcomes with empagliflozin in patients with type 2 diabetes at high cardiovascular risk: results of the EMPA-REG OUTCOME(R) trial. European heart journal. 2016;37(19):1526-34.

23. Neal B, Perkovic V, Mahaffey KW, de Zeeuw D, Fulcher G, Erondu N, Shaw W, Law G, Desai M, Matthews DR, Group CPC. Canagliflozin and Cardiovascular and Renal Events in Type 2 Diabetes. The New England journal of medicine. 2017;377(7):644-57

24. Wiviott SD, Raz I, Bonaca MP, Mosenzon O, Kato ET, Cahn A, Silverman MG, Zelniker TA, Kuder JF, Murphy SA, Bhatt DL, Leiter LA, McGuire DK, Wilding JPH, Ruff CT, Gause-Nilsson IAM, Fredriksson M, Johansson PA, Langkilde AM, Sabatine MS; DECLARE-TIMI 58 Investigators. Dapagliflozin and Cardiovascular Outcomes in Type 2 Diabetes. N Engl $J$ Med. 2019 Jan 24;380(4):347-357.

25. Kosiborod M, Cavender MA, Fu AZ, Wilding JP, Khunti K, Holl RW, Norhammar A, Birkeland KI, Jorgensen ME, Thuresson M, Arya N, Bodegard J, Hammar N, Fenici P, Investigators C-R, Study G. Lower Risk of Heart Failure and Death in Patients Initiated on Sodium-Glucose Cotransporter-2 Inhibitors Versus Other Glucose-Lowering Drugs: The CVD-REAL Study (Comparative Effectiveness of Cardiovascular Outcomes in New Users of Sodium-Glucose Cotransporter-2 Inhibitors). Circulation. 2017;136(3):249-59.

26. Drucker DJ, Nauck MA. The incretin system: glucagon-like peptide-1 recepto agonists and dipeptidyl peptidase- 4 inhibitors in type 2 diabetes. Lancet. 2006;368(9548):1696-705.

27. Pfeffer MA, Claggett B, Diaz R, Dickstein K, Gerstein HC, Kober LV, Lawson FC, Ping L, Wei X, Lewis EF, Maggioni AP, McMurray JJ, Probstfield JL, Riddle MC, Solomon SD, Tardif JC, Investigators E. Lixisenatide in Patients with Type 2 Diabetes and Acute Coronary Syndrome. The New England journal of medicine. 2015;373(23):2247-57.

28. Marso SP, Daniels GH, Brown-Frandsen K, Kristensen P, Mann JF, Nauck MA, Nissen SE, Pocock S, Poulter NR, Ravn LS, Steinberg WM, Stockne M, Zinman B, Bergenstal RM, Buse JB, Committee LS, Investigators LT. Liraglutide and Cardiovascular Outcomes in Type 2 Diabetes. The New England journal of medicine. 2016;375(4):311-22.

29. Marso SP, Bain SC, Consoli A, Eliaschewitz FG, Jodar E, Leiter LA, Lingvay I, Rosenstock J, Seufert J, Warren ML, Woo V, Hansen O, Holst AG, Pettersson J, Vilsboll T, Investigators S-. Semaglutide and Cardiovascula Outcomes in Patients with Type 2 Diabetes. The New England journal of medicine. 2016;375(19):1834-44

30. Jorsal A, Kistorp C, Holmager P, Tougaard RS, Nielsen R, Hanselmann A, Nilsson B, Moller JE, Hjort J, Rasmussen J, Boesgaard TW, Schou M, Videbaek L, Gustafsson I, Flyvbjerg A, Wiggers H, Tarnow L. Effect of liraglutide, a glucagon-like peptide-1 analogue, on left ventricular function in stable chronic heart failure patients with and without diabetes (LIVE)-a multicentre, double-blind, randomised, placebo-controlled trial. European journal of heart failure. 2017;19(1):69-77.

31. Skott P, Hother-Nielsen O, Bruun NE, Giese J, Nielsen MD, Beck-Nielsen $H$, Parving $\mathrm{HH}$. Effects of insulin on kidney function and sodium excretion in healthy subjects. Diabetologia. 1989;32(9):694-9.

32. Rocchini AP, Katch V, Kveselis D, Moorehead C, Martin M, Lampman $\mathrm{R}$, Gregory $\mathrm{M}$. Insulin and renal sodium retention in obese adolescents. Hypertension. 1989;14(4):367-74.

33. Pocock SJ, Wang D, Pfeffer MA, Yusuf S, McMurray JJ, Swedberg KB Ostergren J, Michelson EL, Pieper KS, Granger CB. Predictors of mortality and morbidity in patients with chronic heart failure. European heart journal. 2006;27(1):65-75

34. UK Prospective Diabetes Study (UKPDS) Group. Intensive blood-glucose control with sulphonylureas or insulin compared with conventiona treatment and risk of complications in patients with type 2 diabetes (UKPDS 33). Lancet. 1998;352(9131):837-53.

35. Frye RL, August P, Brooks MM, Hardison RM, Kelsey SF, MacGregor JM, Orchard TJ, Chaitman BR, Genuth SM, Goldberg SH, Hlatky MA, Jones TL, Molitch ME, Nesto RW, Sako EY, Sobel BE. A randomized trial of therapies for type 2 diabetes and coronary artery disease. The New England journa of medicine. 2009;360(24):2503-15.

36. Marso SP, McGuire DK, Zinman B, Poulter NR, Emerson SS, Pieber TR, Pratley RE, Haahr PM, Lange M, Brown-Frandsen K, Moses A, Skibsted S, Kvist K, Buse JB, Group DS. Efficacy and Safety of Degludec versus Glargine in Type 2 Diabetes. The New England journal of medicine. 2017;377(8):723-32.

37. Shewan LG, Coats AJS, Henein MY. Authors' Responsibilities and Ethical Publishing. International Cardiovascular Forum Journal 2018;13:3-4, DOI: 10.17987/icfj.v13i0.525 